UCRL-JC-128799

\title{
Estimating Changes in Rock Permeability Due to Thermal-Mechanical Effects
}

\author{
H.F. Wang \\ S.C. Blair \\ P.A. Berge
}

This paper was prepared for submittal to the

American Nuclear Society

1998 International High-Level Radioactive Waste Management Conference

Las Vegas, $N V$

May 11-14, 1998

October 1997

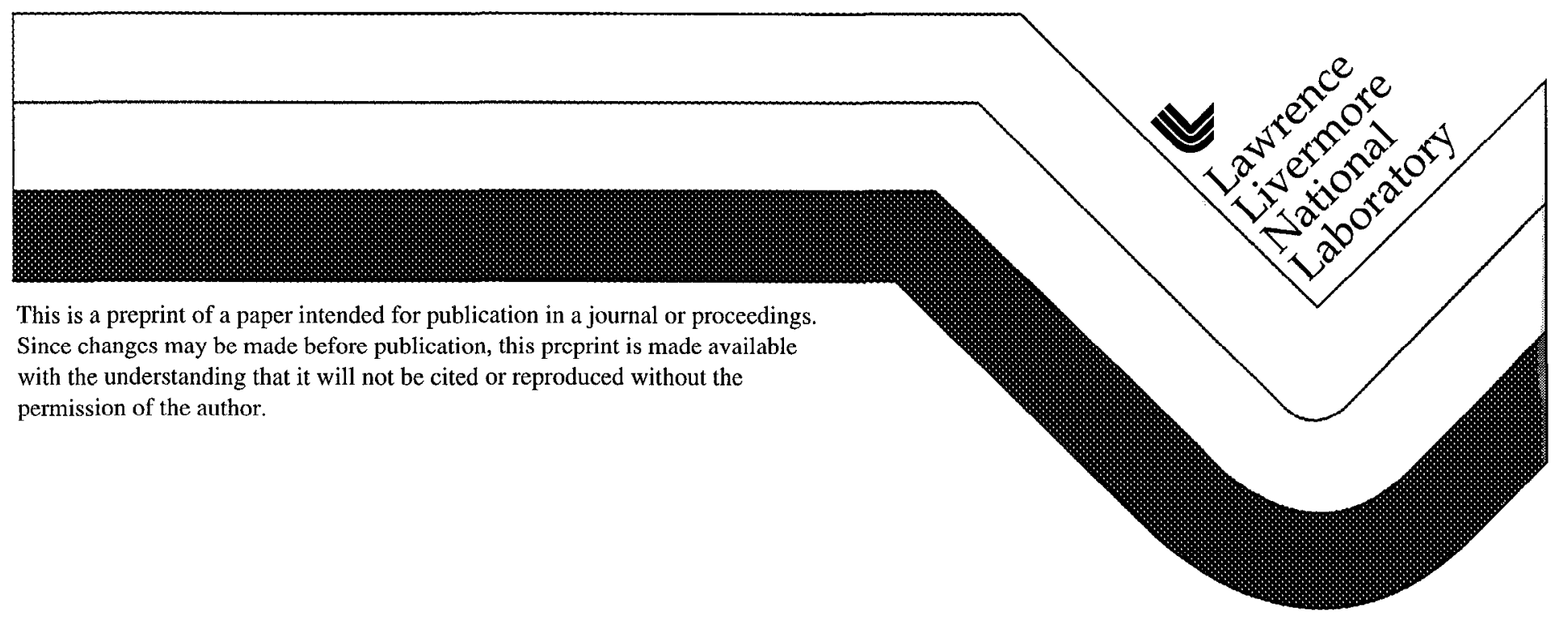




\section{DISCLAIMER}

This document was prepared as an account of work sponsored by an agency of the Linited States Govemment Neither the United States Government nor the Lnis ersity of California nor any of their employess, makes any warranty, express or implied, or assumes any legal liability or responsibiity for the accuracy, completeness, or usefulness of any information, apparatus, product, or process disclosed, or represents that its use would not initinge privately owned rights Rererence herein to any specific commercial product, process, or sen ice by trade name tademark, manufacturer, or otherwise, does not necessarily constitute or imply its endorsement, recommendation, or faloring by the Linited States Govemment or the Lniversity of Califomia The view's and opinions of authors expressed herein do not necessarily state or reflec: those of the Lnited States Goremment or the Liniversity of Caiformia, and shall not be used for aciersing or product endorsement purposes 


\section{ESTIMATING CHANGES IN ROCK PERMEABILITY DUE TO}

\section{THERMAL-MECHANICAL EFFECTS}

Herbert F. Wang

University of Wisconsin

Madison, Wisconsin

53706

608-262-5932

\author{
Stephen C. Blair \\ Lawrence Livermore National \\ Laboratory \\ PO Box 808 \\ Livermore, CA 94551 \\ 925-422-6467
}

\author{
Patricia A. Berge \\ Lawrence Livermore National \\ Laboratory \\ PO Box 808 \\ Livermore, CA 94551 \\ 925-423-4829
}

\section{ABSTRACT}

This paper presents results of a modeling study of changes in fracture permeability due to thermal-mechanical effects associated with the potential geological repository at Yucca Mountain. A methodology for estimating changes in permeability is developed and applied to the Drift Scale Test (DST) now being conducted in the Exploratory Studies Facility (ESF) at Yucca Mountain. Temperature, stress, and displacement of rock in the heated zone are presented along with predicted zones where slip on fractures may occur. The zones of predicted fracture slip are used as a basis for predicting where permeability may be changed. This new procedure goes beyond previous models that relate stress to strain or displacement, and provides information about rock response that is needed for design of future tests at Yucca Mountain. Our results also contribute to the understanding of coupled processes in the near-field environment of a repository.

\section{INTRODUCTION}

The Yucca Mountain Site Characterization Project is evaluating Yucca Mountain, Nevada, as a site for development of a geologic repository for the permanent disposal of nuclear waste. The permeability of the host rock is an important parameter for characterizing the hydrologic environment of a proposed repository site, and for evaluation of the hydrologic behavior of a proposed repository design. That is, knowledge and understanding of rock permeability and how it may change over the lifetime of a geologic repository is important to the prediction and evaluation of repository performance.

It is well known that the rock mass forming the potential repository horizon at Yucca Mountain is a fractured, densely welded, ash-flow tuff, and the in situ permeability of the rock mass is due to the fractures [1]. Moreover, any changes in rock mass permeability due to thermal-mechanical effects can be attributed to thermalInechanical behavior of the fractures, as thermal-mechanical effects on matrix permeability are expected to be small.
Recently, Barton et al. [2] presented convincing evidence that hydraulically conductive fractures in the Dixie Valley geothermal field are critically stressed potentially active normal faults, based on the Mohr-Coulomb frictional slip criterion. Their work is significant because, while it has been widely recognized that only a few of the fractures in a rock mass are hydraulically conductive, until their work there has been no way to identify the conductive fractures. The implication is that the occurrence of slip on the critically stressed fractures causes increased permeability.

In the work reported here we investigate the influence that thermal-mechanical stresses associated with the DST can have in changing the permeability of the host rock.

\section{WORK DESCRIPTION}

Our methodology is as follows: The thermal-mechanical (T-M) stress field for a cross-section of the DST is calculated at selected time intervals from the start of the DST. We used the finite-difference code FLAC [3] to calculate stress and displacement for the DST. Input to this calculation includes the temperature field calculated using a hydrothermal model at each of the selected times. The shear stresses predicted on selected fracture planes are then used with the MohrCoulomb criterion to ascertain whether or not pre-existing fracture sets slip because of thermal stresses. Then, a fracture flow model that includes shear offset is used to estimate permeability changes for these fracture sets. The analysis is preliminary because it is 2-D and assumes an elastic medium whose properties do not change even when frictional slip and stress redistribution are likely to have occurred. The analysis also neglects permeability reductions as a result of increased normal stresses and fracture closure during heating.

In broad terms three fracture sets have been identified in the ESF: set \#1 is a steeply dipping set of fractures striking $\mathrm{EW}$, set \#2 is a steeply dipping set of fractures striking NS, and set \#3 is a subhorizontal set of fractures striking EW [4]. The axis of the heated drift is oriented EW; hence set \#1 and set \#3 have their strike perpendicular to the plane of our model. Thus, calculations of shear slip for vertical and 
horizontal fractures correspond to slip on fractures in set \#1 and set \#3, respectively.

To estimate regions of increased permeability for the DST we assume that permeability will double at any location where slip on fractures is predicted to occur. This assumption is based on combining the standard parallel plate relationship between flow in a fracture and the fracture aperture, with the fracture aperture distribution model of Brown [5]. We also assume that slip on one set of fractures does not interfere with slip on any other set, and that changes in permeability predicted for one set of fractures can be added linearly to changes in permeability predicted for the other sets. Thus, if a zone of enhanced permeability predicted for slip along a vertical set of fractures overlaps a zone of enhanced permeability predicted for a set of horizontal fractures, we predict a total permeability enhancement of 4 times for the overlapping region.

\section{RESULTS}

Predicted zones of enhanced permeability due to excavation of the DST and prior to heating are shown in Figure 1a. This figure shows that excavation of the drifts is predicted to increase the permeability of the rock surrounding the drift in a region extending up to one-half drift diameter into the drift wall. This is not unexpected, and many mining studies have shown that permeability of wall rock is often increased in underground excavations.

For the vertical fracture set our results show that the zone of enhanced permeability predicted to occur after onehalf year of heating (i.e., heating to a temperature of $\sim 100$ ${ }^{\circ} \mathrm{C}$ at the drift wall) consists of two large wedge-shaped regions, one above and the other below the plane of the wing heaters that are deployed in the test. These areas are illustrated in Figure $1 \mathrm{~b}$ using the light shading, and are essentially symmetric about the horizontal wing heater plane. The scale of these regions is on the order of the separation of the heated drift and the observation drift, and the width is on the order of half the drift separation (i.e., $13.5 \mathrm{~m})$.

Regions of changed permeability for horizontal fractures occur between the wing heater plane and the observation drift, and are centered at a distance about four meters above and below the plane of the wing heaters. These regions are illustrated with medium shading in Figure $1 \mathrm{~b}$.
Permeability is predicted to be enhanced by 4 times in zones which occur where both fracture sets are expected to slip. These zones are also symmetric above and below the wing heater plane and comprise approximately one-fourth of the total area of permeability enhancement and are shown with the darkest shading in Figure $1 \mathrm{~b}$.

We also predict that zones of enhanced permeability will grow with time, while maintaining the same basic shape formed after 0.5 year of heating. Zones of enhanced permeability may recede outward from the heaters as heating continues. This is illustrated in Figure 1c which shows the zones of enhanced permeability after 4 years of heating. Comparison with stress plots shows that the permeability is enhanced in areas of high thermal gradients as is expected from the formulation, because such areas hae high stress gradients.

\section{DISCUSSION AND CONCLUSIONS}

We have provided a methodology that can now be used to estimate changes in permeability due to thermalmechanical effects. Our result is quite intuitive. However, to our knowledge, no work to date has presented such a methodology for relating changes in the stress field to changes in the permeability of the rock mass. Our results indicate that thermal-mechanical effects on permeability may extend over significant portions of rock heated during the Drift Scale Test.

\section{REFERENCES}

1. Wilder, D. G, 1996, Near-field and altered zone environment report, vols I \& II, UCRL-LR-124998, Lawrence Livermore National Laboratory, Livermore, CA

2. Barton, C. A., S. Hickman, R. Morin, M. D. Zoback, T. Finkbeiner, J. Sass, and D. Benoit, 1997, Fracture permeability and its relationship to in-situ stress in the Dixie Valley, Nevada, Geothermal Reservoir, in Proc. Twenty-Second Workshop on Geothermal Reservoir Engineering, 6 pp., Stanford University, Stanford, CA, Jan. 27-29, 1997.

3. Itasca Consulting Group, Inc, 1993, FLAC User's Manual, vol I-III, Minneapolis, MN. 


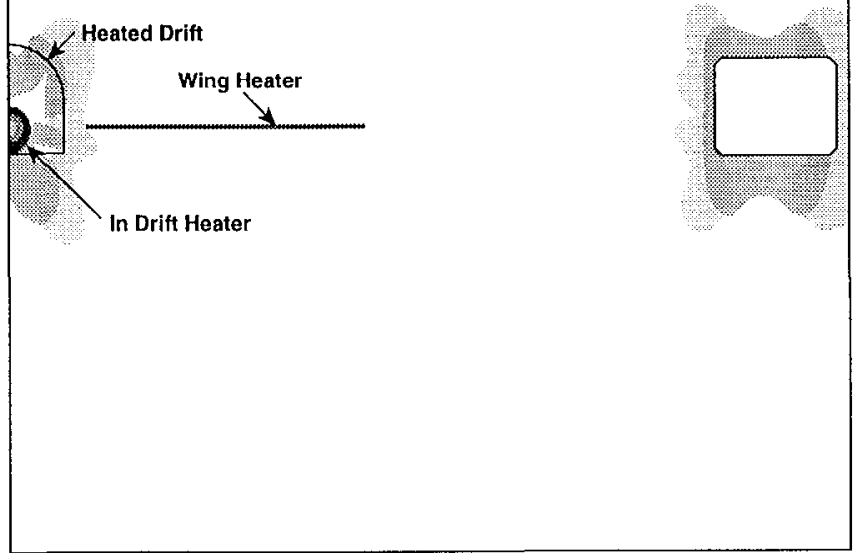

Figure 1a. Zones of enhanced permeability due to excavations associated with the Drift Scale Test.

4. Albin, A. L., W. L. Singleton, T. C. Moycr, A. C. Lee, R. C. Lung, G. L. W. Eatman, and D. L. Barr (1997), Geology of the Main Drift -Station 28+00 to 55+00, Exploratory Studies Facility, Yucca Mountain Project, Yucca Mountain, Nevada, 208 pp. + photos + maps, Bureau of Reclamation and U. S. Geological Survey, Denver, CO.

5. Brown, S. R., 1995, Simple mathematical model of a rough fracture, J. Geophys. Res., 100, 5941-5952. Brown, S. R., and R. L. Bruhn, 1997, Fluid permeability of deformable fracture networks, SAND970159, Sandia National Laboratories.

\section{ACKNOWLEDGMENT}

This work was supported by the Yucca Mountain Site Characterization Project. Work performed under the auspices of the U.S. Department of Energy by Lawrence Livermore National Laboratory under contract W-7405ENG-48

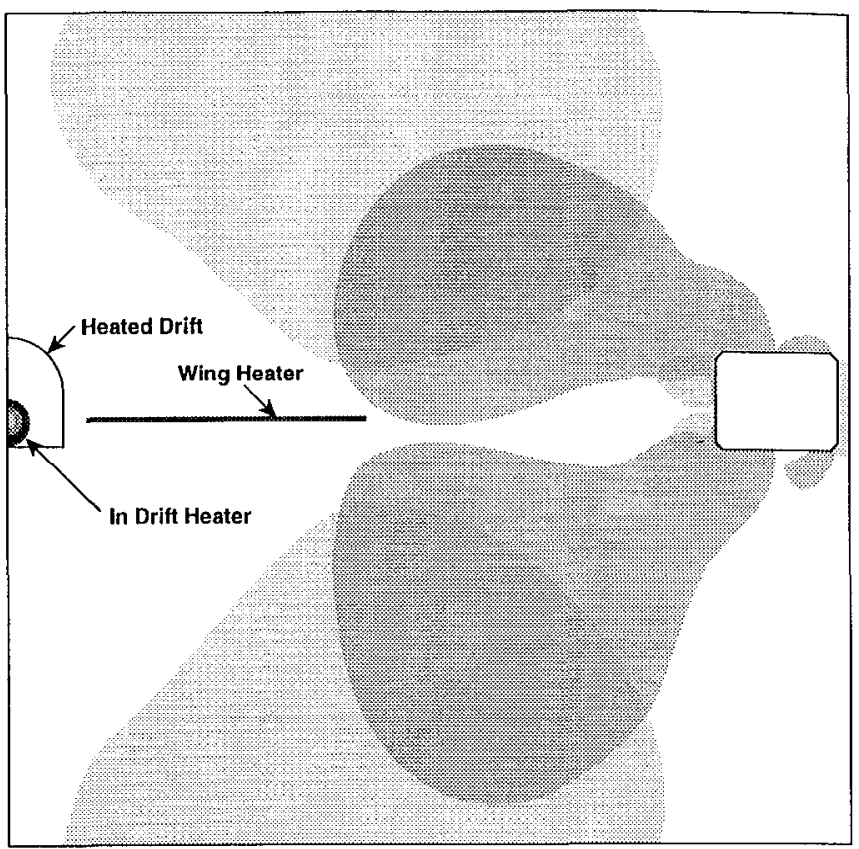

Figure 1b. Zones of enhanced permeability after 0.5 years of heating in the Drift Scale Test. Drift wall is aproximately $100^{\circ} \mathrm{C}$.

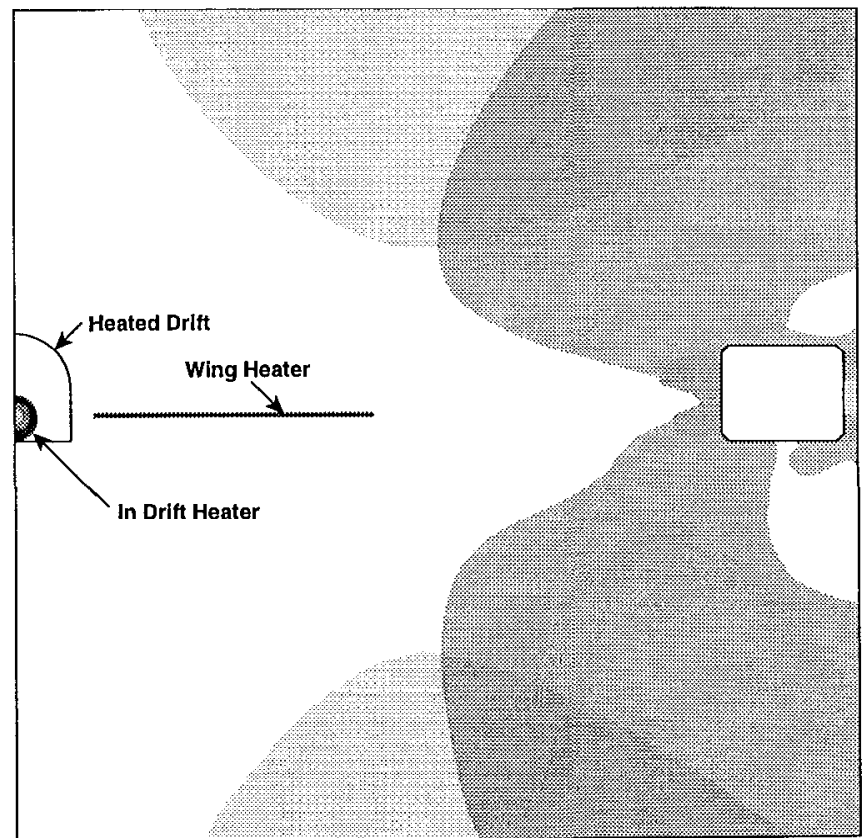

Figure 1c. Zones of enhanced permeability after 4 years of heating in the Drift Scale Test. Drift wall is approximately $325^{\circ} \mathrm{C}$. 


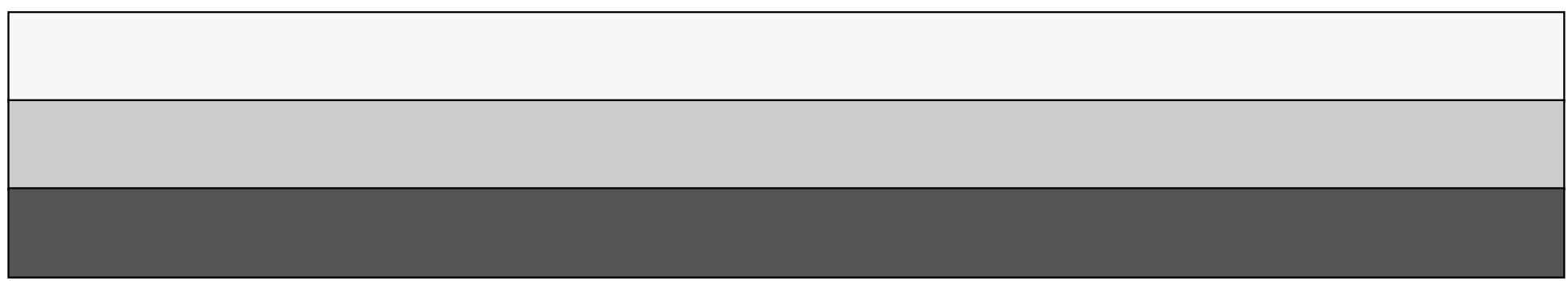

